\title{
Ethical consumers: an exploratory investigation of the ethical food consumption behaviour of young adults in the North East of Scotland.
}

OKE, A., LADAS, J. and BAILEY, M. 


\section{British Food Journal}

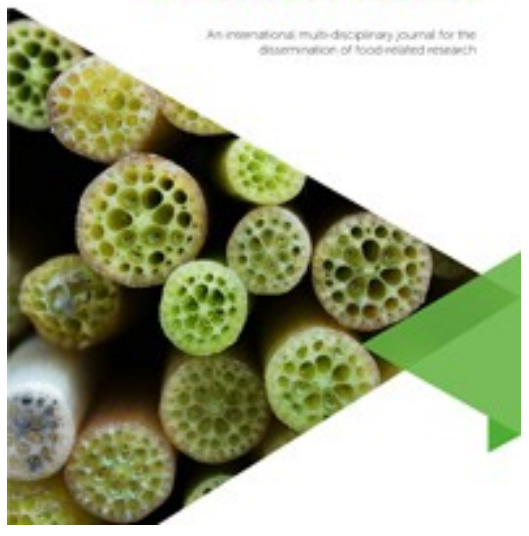

Ethical Consumers: An exploratory investigation of the ethical food consumption behaviour of young adults in the North East of Scotland

\begin{tabular}{|r|l|}
\hline Journal: & British Food Journal \\
\hline Manuscript ID & BFJ-10-2019-0801.R2 \\
\hline Manuscript Type: & Research Paper \\
\hline Keywords: & $\begin{array}{l}\text { Buying Behaviour, Cosumerism, food consumption, Food products, } \\
\text { Organic foods, Vegetarians }\end{array}$ \\
\hline
\end{tabular}

\section{SCHOLARONE ${ }^{m}$ Manuscripts}




\title{
Ethical Consumers: An exploratory investigation of the ethical food consumption behaviour of young adults in the North East of Scotland
}

\begin{abstract}
Purpose

This study aims to explore the motivation as well as barriers for ethical food consumption behaviour by focusing on the food consumption pattern of young adults in the North East of Scotland. Considering the recent involvement of young adults in environmental activism, consumption behaviour of young adults in the North East of Scotland, an oil-based community, presents essential research interest to understand whether young adults often contemplate the consequences of their lifestyle.

\section{Design/methodology/approach}

The authors explored the perceptions of 10 purposive recruited young adults using semistructured interviews to understand factors underpinning consumer's decision-making towards ethical food products.

\section{Findings}

The study reveals three key factors influencing ethical food consumption behaviour among young adults. The findings show that personal health and wellbeing are the main reasons

why consumers engage in ethical food consumption. Also, it is observed that information facilitates decision-making by raising awareness regarding the social, environmental and health consequences of food production-consumption. Further, the findings show that situational attributes, such as product price and product availability, are creating dissonance when engaging in ethical food consumption.

\section{Originality/value}

This study contributes to sustainability research and the ongoing debate on consumerism by exploring ethical food consumption behaviour and highlights the need to address situational challenges, such as product price and availability. The study suggests that interventions to address current consumption patterns should also emphasise the social and personal benefits of food consumption rather than the environmental benefits that have been the focus of prior research.

Keywords: Ethical; Sustainability; Consumer; Behaviour; Food; Consumption; Organic; Supply Chain; Vegetarianism.

Introduction 
The exponential rate of population growth is not only increasing the global food demand but also exerting pressure on agricultural food production to meet the consumer's daily food and nutritional needs (Crist et al., 2017; Sala et al., 2017). Although the utilisation of resources and products plays a central role in driving the global economy, especially in contemporary society (Harari, 2011; Vantamay, 2018), the question is whether the environment can sustain the present rate of resource consumption. It should be noted that resource consumption has been intensified over the past 50 years by almost $190 \%$ leading to the production of waste that outweighs the absorptive capacity of the environment

(Kostadinova, 2016). For example, about 89 million tonnes of food is wasted every year in the EU and could increase to 126 million tonnes per annum by the year 2020 if no drastic action is introduced (Baker et al., 2019).

Also, the overconsumption of agri-food products is not only affecting the health of the planet but also have negative effects on people's health. According to Sakadevan and Nguyen (2017), livestock production, especially meat and dairy products, is contributing around $17 \%$ to the overall carbon emissions. Other health issues such as obesity, heart problems, and other health-related problems due to the dietary shifts, are raising the health costs (Reisch et al., 2013). For example, the monetary value of obesity to Scotland is estimated to be about $\mathrm{f} 1$ billion a year and may increase to about $\mathrm{f} 4.5$ billion per annum by taking the broader economic cost into the equation.

Considering that food consumption is related to behaviour (Kareklas et al., 2014; Pappas, 2016), any attempt to address food production and consumption issues should account for the effects of population growth and its associated consumerism. According to Harari (2011), consumerism has changed over the past years from focusing almost solely on the environmental issues towards a more conscious ethical consumption and social justice. Also, the increasing media coverage, coupled with the availability of alternative products (Pappas, 2016; Wang and Hao, 2018) is introducing a new way of thinking regarding resource consumption. In the UK, like the rest of other developed countries, consumers, are driving the demand for ethical products, and the increasing demand for ethically produced

commodities is gaining momentum, especially among young consumers (Fraj and Martinez, 2006; Kaufmann et al., 2012; Kostadinova, 2016). Further, the sales of ethical products are growing and there is an opportunity to increase the current margin, especially with an understanding of what drives ethical consumption (Crist et al., 2017; Govind et al., 2019). For instance, the UK vegan's population has considerably increased from 150,000 in 2014 to about 600,000 in 2019 (Vegan Society, 2019). There was an increment of about 16\% in ethical food and drink consumption, a significant increase since 2012, mainly due to the growing sales of vegetarian products (Ethical Consumer Research Association, 2018). 
Despite the positive outlook of ethical food products, such as organic and vegetarian products, there is no consensus regarding the motivations for ethical food consumption and the present knowledge regarding why consumers behave the way do is insufficient. While there are attempts (such as Han and Hansen, 2012; Kaufmann et al., 2012) to explain consumption behaviour, efforts are focusing extensively on personal and psychological factors, with inconclusive findings. According to Reisch et al. (2013), consumers consider organic products to be healthier than the inorganic counterparts while Birch et al. (2017) argued that concerns of chemicals in inorganic foods are influencing the consumption of organic products. Despite the quest for ethical food products, the mass production of conventional food products may overshadow their sustainability (Pappas, 2016; Peattieand Peattie, 2009).

The renewed interest in sustainability (Vermeir and Verbeke, 2006), especially among young adults with the creation of a new dynamic movement of activism (Scarce, 2016), may encourage ethical food decision-making. With the recent sharp rise in local interest in the community of activism that is inspired by the activities of "Extinction Rebellion", the question is whether young adults, who are mostly the protestors across the world, ever contemplate their consumption behaviour, including their lifestyle choices. Considering that past studies (such as McCarthy and Liu, 2017; Vermeir and Verbeke, 2006) on green behaviours have segmented consumers using socio-demographics, especially age, this study seeks to explore food consumption behaviour of young adults.

The goal is to provide insights and to understand how ethical food consumption behaviour is framed by young adults to address the issues associated with consumerism. With this understanding, it seems appropriate to conduct a small exploratory study to get a flavour of ethical food consumption behaviour of young adults. According to Rettie et al. (2012), the understanding of ethical consumption behaviour may reduce the challenges of promoting and marketing ethicalfood. Also, the study context is suitable for such an exploratory study considering that a large number of young adults come to the buoyant oil and gas community of the North East Scotland to study and work. As this population is attracted to the city by

its oil and gas opportunities, the sample represents people who are considered to be unsustainable and unethical due to their involvement in the operations of the energy sector, especially oil and gas activities (Smith and High, 2017). Also, the study context is important for this exploratory study taking into account that the area is traditionally sensitive to the consumerist ideas due to its geographical location (Insight Department, 2015).

\section{Methods}


To achieve the overarching goal of this study, perceptions of young adults were explored regarding their food consumption behaviour to explain the motivations and barriers to their consumption behaviour. This exploratory investigation is necessary considering the growing community of environmental activism (De Hoop and Jehlička, 2017; Scarce, 2016), especially among young adults, across the world. As a result, the following research questions were addressed in this study:

1. What are the perceptions of consumers regarding ethical food products?

2. What influences consumer's decision-making process, including the consumers buying of ethical food products behaviour?

3. What are the strategies or interventions that can be introduced to promote ethical food consumption?

The study adopted a qualitative approach to gain a deeper understanding of ethical consumption patterns by exploring how consumers perceive and make sense (Creswell and Creswell, 2018) of the world of food. Given that this is an exploratory study, an interpretive perspective, which is concerned with the understanding of individuals' perceptions and observations, interpretation of experiences, beliefs and opinions (Bryman, 2016; Guest et al., 2006), of young adults seemed appropriate.

Consistent with the interpretive approach, semi-structured interviews were used to explore food consumption behaviour of young adults in the North East of Scotland. A purposive sampling method was adopted to recruit key participants based on their relevance to the research theme (Baker, 2003; Bryman, 2016) and in answering the research questions. Relevant participants who could contribute to the goals of this study were contacted by visiting locations that are known for ethical food products in Aberdeen. The study participants (such as vegans, vegetarian, and organic food consumers) were self-identified as ethical consumers based on their consumption behaviour. By aiming to observe perceptions in a homogenous community, 12 interviews are sufficient (Guest et al., 2006); however, 10 in-depth semi-structured interviews were conducted for this study (see Table 1).

\section{(Please insert Table 1 here)}

Although the interview process was discontinued at the saturation point, a sample size as used in this study was considered appropriate given the exploratory nature of this study, in that the interviews were sufficiently in-depth (with each interview lasted for about 60 minutes) and generated sufficient data to answer the research questions (Baker, 2003; Guest et al., 2006). 


\section{Data analysis}

This study adopts a thematic analytical inductive (Bryman, 2016; Creswell and Creswell, 2018) approach using an iterative process of data collection and analysis to reveal common themes in the way young adults frame their food consumption behaviour. The interview transcripts were checked and rechecked to ensure that the perceptions of young adults regarding food consumption were analysed and presented with quality, rigour and trustworthiness (Davies and Dodd, 2002; Ryan and Bernard, 2003). Before the analysis, the transcripts were discussed with the research participants for correctness andaccuracy.

Having established the accuracy of each transcript, the transcripts were read multiple times by the authors to understand the data while anticipating possible codes and themes that may emerge from the data. The data analysis process was facilitated by NVivo 11, a computer-aided qualitative data analysis sof tware (CAQDAS) (Bazeley and Jackson, 2013); however, the authors assessed the codes and patterns generated from the data against the transcripts. Apart from keeping an audit trail of the interview process, codes and categories that finally emerged from the data based on the authors' agreement were further probed using relevant studies on consumer behaviour.

\section{Findings}

\section{General perceptions}

It is evident from the data that all the participants have positive perceptions about sustainability that may explain their dispositions towards ethical food consumption, although what constitutes ethical food is different from participants to participants. Based on the participants' perceptions, the concept of sustainability is important to avert the depletion of natural resources. It is observed that ethical food consumption is crucial for all participants with many of them being vegetarian and pescatarian. Maintaining a healthy lifestyle is the common denominator in their consumption, and this study argues that consumers with positive perceptions towards ethical products are willing to buy and consume ethical food products. All the interviewees have a strong belief and positive feelings towards sustainability which aligned with their favourable evaluations of ethical food products. While these perceptions may translate to ethical food consumption, there is a need to establish the motivations for these perceptions such that young adults' perceptions are used as a lens to explain why consumers engage in ethical food consumption.

\section{Personal health and wellbeing}

The findings of this study show that young adults' decision to purchase ethical food products is primarily due to their health and wellbeing. When asked if they consider the impact of 
their purchase decisions, for example, on themselves, the environment and society as a whole, the participants ranked their health as the main priority. Participants attributed these motivations to personal health issues and wellbeing, such as food allergies,

intolerances, and the general desire to be healthier and fit. According to this worldview, consumers are willing to be more responsible for their food choices; however, the biggest incentive to do so is their health and wellbeing. For example:

“I'm doing it for my personal health, due to intolerances. I can't consume gluten or milk. Often, I choose products for vegans etc. I do it because I'm limited to those products." [Mila].

"I think naturally the most immediate, so myself. If something has an immediate impact on me, then my attention will be drawn to this first. Then those around

me and I would put the environment and the whole world on the same page as third parties involved. I care about them, but first and foremost, I'll watch out for myself." [Lynn].

Contrary to Kostadinova (2016), but consistent with other studies (such as Kareklas et al., 2014; Vantamay, 2018), the findings of this study suggest that the primary motivation for young adults to consume more ethically is the perceived value they receive in terms of their health, which reflects the dominant egoistic values. According to Kostadinova (2016), proenvironmental behaviour is a function of pro-social and moral values towards the environment, whereas Kareklas et al. (2014) and Vantamay (2018) observed a relationship between consumption behaviour and self-enhancement values. Nonetheless, this study argues that the dominant values may have a positive or negative effect on ethical food

buying behaviour. For instance, those with strong egoistic values and believe that ethical food would enhance their health and wellbeing may consume more ethical food products.

This has a dual effect in that consumers may not realise that they are improving the environment and animal wellbeing by being egoistic regarding their ethical food consumption behaviour. On the contrary, egocentric consumers with no interests in the health benefits of ethical food may purchase and consume alternative products rather than ethically produced food that may improve the environmental and social wellbeing.

\section{Perceptions of self}

The findings of this study show that ethical food consumption behaviour is an integral part of self that defines the identity of young adults. From the participants' comments, the ability to contribute to a good cause, such as the preservation of the natural ecosystem and the protection of animal rights, is an important motivation to engage in ethical food consumption. Being conscientious in their purchase choices and its impact, including 
concern about self, provides young adults with the opportunity to reaffirm their sense of self with positive effects on their belief-system.

The feelings of self-actualisation that inform the participants self-identify as ethical consumers is an essential driver for their consumption behaviour. Although the feeling is personal, internal, and psychological, it is associated with a sense of pride and selffulfilment in doing something right and worthwhile. All the study participants feel a sense of personal satisfaction and self-actualisation, including a feeling of harmony with nature. According to Lynn for instance,

"Peace of mind. Certain personal satisfaction if you believe what you do is good. I like the consistency; when I do that kind of thing, it helps to reaffirm in myself. Reminds me exactly what I believe in it shows that I am consistent in this. I like that this is a part of my identity and it manifests itself that way."

Based on the findings, self-actualisation coupled with the sense of personal responsibility reinforces environmental orientated behaviour by appealing directly to the consumer's egoistic motivation for ethical food consumption. Although personal satisfaction that young adults derive from engaging in ethical food consumption contribute to self-actualisation, the perceptions of self further explain how the participants evaluate their capability, knowledge, and resources for ethical food consumption.

\section{Effects of the Social Context of Consumption}

Interviewees are influenced in their decision to adopt a more ethical lifestyle through family members, partners, or peers. Besides the effects of self-identify, the dominant social context of consumption explains the perception of significant others regarding consumption

behaviour. Considering that the participants are young adults, the prevailing social norms are an essential contributor to their ethical food consumption behaviour due to the desire to identify with a social group or to feel a sense of approval and acceptance. For example,

"My brother first decided to become a vegetarian, and then I told him he is not going to survive like 6 months because he would lack lots of nutrients. But he kept going, and at the same time a lot of athletes went vegan, and then I had a closer look at it and decided to try it myself, and it went very well." [Tom]

"At the beginning when I met him I never thought about becoming vegan . . But I think, during the time, when I thought I could never become vegan I didn't know how the industry was working. In the way he influenced me was to show me all those things, and then it was up to me." [Sarah]. 
Considering that young adults may encounter personal and social dilemma in their ethical consumption decision making, the sense of identifying with a dominant social norm could influence their ethical food consumption. Based on the findings of this study, the social relationships of young adults have a strong influence on their lifestyle and the choice they make regarding their food consumption.

\section{Contributions of environmental concern}

Another important factor that emerged is the extent to which young adults are concerned about the environment, and this drives the changes in their daily buying behaviour. It is observed from the findings that young adults are strongly concerned about the health and sustainability of the planet, including the planetary outlook for future generations. For instance,

"Of course, I could be like the planet will be fine for another 50 years or so and then I am gone. But I don't want to do that especially as a very familyorientated person. I don't want to bring my kids and their kids into somewhere where it is unliveable." [Mila].

The observed environmental concern explains consumers' disposition in evaluating what is right or wrong and favourable or unfavourable regarding the effects of their actions on the environment. Although the study participants are aware of many environmental problems, such as climate change and biodiversity loss, the concern may not necessarily translate to ethical consumption behaviour.

Also, there is a consensus among the participants that consumers have a duty-of-care to protect the environment and future generations through their consumption choices. As a result, there is an active attempt by young adults, including the millennials, to influence and change the current buying behaviour through environmental activism and protests, especially in the UK. According to Lynn, for example,

"I think people messed up big time. That is also why as a human being I care what I do because I know that our actions cause this . . . I think trying to defend the environment is not enough, changing people's behaviour and mentality is more effective."

Despite the difficulty in changing consumer behaviour towards ethical food, there is a strong indication that environmental concern may have positive effects on how and why resources are consumed considering the growing community of environmental activism, particularly among young adults. 


\section{Concern for animal welfare}

Encouraging consumers to consume ethically by buying ethical food products while preventing food waste is becoming far more challenging, especially in the world of mass production of foods. The degree of cruelty being suffered by animals as perceived by the study participants plays a vital role in their consumption choices to be either vegan or vegetarian. Although animal cruelty is beyond food consumption, animals are being used in scientific research, clothing, game, and other household decorative ornaments. According to the participants, humans have the responsibility to sustain a healthy ecosystem by ensuring the welfare of animals and protecting biodiversity. There is a general perception that transportation and killing of animals for human consumption are unethical and driven by pure greed with the mindset that humans can dominate and are more important than animals. For instance,

"Eating animals is basically linked to the fact that humans are more important than other species and this is very discriminatory. " [Nick]

"I think human behaviour is an act of greediness. It is not a sustainable cycle to raise that many animals and overfeed or force-feed them and slaughter them only for human consumption. . . the input is just too high and I find it as an inefficient or unsustainable way to sustain human appetite. " [Peter].

From the findings, animal and animal products consumption is unnecessary due to a variety of alternative products that could satisfy human nutritional needs. According to Lizzy,

"You can electrocute them (animals), so they might not feel that (pain) much but who gives you the right to kill the animal if you have a choice? You have achoice to eat other things."

\section{Effects of information and knowledge}

The quality of information and the reliability of its sources affect young adult's understanding of ethical food products and subsequently influence their consumption behaviour. According to the study participants, the information gathering and acquisition of knowledge are fundamental to their decision-making process. The study participants are aware and knowledgeable about the harmful impacts of food choices on people's health, animal welfare, and the environment. A deeper understanding of the negative consequences of unethical production and consumption was identified as a motivation for many young adults to become vegan or vegetarian. For example, 
"I think the knowledge acquired watching, for example, a documentary really made a difference in the decision to become and stay vegetarian for a long time, in this case, 6 years. " [Nick]

"Before I was very unconscious, and I used to eat at McDonald's or KFC. But my whole perception changed when I had a look at the food industry and how it works behind the scenes" [Tom].

The available information and its accessibility provide a basis for people to be more ethical in their buying behaviour. Nevertheless, some comments alluded to the lack of general knowledge about the consequences of food consumption, which may suggest that consumers are not always informed about the implications of their actions. Despite the increased interest in sustainability, the lack of knowledge about the consequences of food consumption suggests a lack of conversation on ethical consumption in people's day-to-day activities. Also, it may indicate that the current marketing strategies for conventional products that are mass-produced are more effective in influencing the way people experience the reality of food when purchasing and consuming food items.

Taken together, a lack of authenticated information and insufficient knowledge are major barriers to ethical food consumption behaviour. For instance, Mike consented that,

"The main difficulty is that all the information is here, but you won't get it if you don't want to get it. However, I believe there should sufficient and right information on how food products are produced so consumers could make informed-decisions regarding ethical consumption ".

\section{The question of responsibility}

The consensus among the study participants suggests that humans are responsible for the current problems. The problems are complexified by the marketing strategies that promote consumerism, and many industrial activities that encourage overproduction, with the actions of policymakers that fail to monitor and enforce policies. The belief that consumers' efforts will have positive effects contributes to the study participants' decision-making process while accepting the responsibility for their behaviour. Having the ability to reduce

the current consumption problems by making ethical choices that promote sustainability but refusing to act by rejecting the responsibility is unethical according to the study

participants. According to Mila for example,

"The calmness of my consciousness, that I am doing something good. Something good for the environment. To some extent, the animals that you eat had a great 
life, and they didn't suffer. I feel like everything just comes down to you knowing you have done something good. There is this option for you, and if you can, and you don't do it out of laziness, then it's a shame and its selfishness."

Irrespective of actions across the entire food production-consumption supply chain, consumers are the focal point and have the responsibility to make ethical decisions that can nudge industrial operations towards sustainability. The ability to develop a sense of responsibility as consumers contributes to the formation of moral obligations towards ethical food products with positive effects on consumption behaviour.

\section{The issue of price sensitivity}

According to the findings of this study, price is a significant influence on consumer's buying behaviour although some participants are willing to pay a premium price for ethical food products, such as organic foods. The interviewees perceive that the benefits of ethical products, such as organic and local produce, outweigh the costs suggesting their preparedness to pay a little more. To some participants, price is not a strong barrier.

"I am willing to pay more for higher quality and taste. "I like it when it's a bit higher priced and when it's obvious where it comes from, where it is produced and packed." [Lizzy]

"In the beginning, it was a crucial factor I was thinking of, but with time I think it is worth it since it is better for your health and the environment around you."

[Sarah].

However, since all the interviewees are young adults, price represents a crucial factor in their decision-making process, and there is a certain threshold to what the majority may be willing to pay. Even though the respondents showed the willingness to buy more ethical products, it is difficult for some consumers to act according to their dispositions due to the products' price.

"Sometimes I buy foods which are imported from other countries even though maybe it is not that great, but I don't want to spend that much money on sustainable or local food. " [Jenny]

"I think that my main motivator is the price may be in the future I will buy it more when I'm financially stable" [Nick].

The effect of price on ethical food consumption is mixed, although price may be less of an issue once consumers' materialistic needs are satisfied. 


\section{Perceived accessibility and availability of ethical products}

Availability and accessibility of ethical food products were identified as one of the major determinants of ethical food consumption behaviour. Although these factors are important motivators, the current agro-production and retailers' actions, especially in the UK, suggest that many ethical products are less available and accessible to consumers. According to the participants, non-availability and lack of varieties of ethical food products, such as organic food, in retail outlets are barriers to ethical food consumption behaviour. According to Nick for example,

"I don't think I really had the chance to buy any ethical food product because they were not actually in the supermarket in the category of the food I was lookingfor. For example, I bought apples, and those were not ethically sourced apples, not that I am aware of "

"I believe some sections within the store should be allocated for ethical and healthy foods so they are more visible to customers. The layout of many stores where organic products are mixed with other products is confusing to many consumers" [Peter].

The lack of accessibility is complexified by the current marketing and information dissemination strategies regarding ethical products in that the participants perceived that the big supermarkets are not doing enough in making ethical food products more accessible to their customers. Although conventional foods are mostly advertised in the media, the study participants felt that the advertisement of ethical products could increase the awareness about ethical foods and strengthen the ongoing efforts to consume ethically. The current promotion strategies are making it challenging for consumers to translate their norms, values, and self-identity into ethical consumption behaviour. For example,

"It is not accessible and available. It is much easier to go to the cheapest supermarket not caring at all about the environment or animals . . . everything is confusing and difficult to identify products that are organic or produced locally." [Lisa].

While young adults are conscientious in their decision-making, they believe that incentives and opportunities to translate their decisions into ethical buying behaviour are not enough. The study participants, therefore, believed that retailers and their existing marketing strategies for ethical foods should be improved to nudge consumers towards ethical food products. According to the participants, consumers would need to make a more considerable 
effort in searching for ethically produced foods. The perceived inconvenience due to the lack of accessibility and availability is one of the rationalisations for engaging in unethical food consumption behaviour.

\section{Ethical food consumption and sustainability}

Packaging, especially with plastics, is another key concern for the study participants. From the participants' views, the fundamental question is whether ethical food consumption is contributing to sustainability. On the one hand, participants perceived that ethically produced foods, such as organic fruits, are often over-packaged with plastic materials, which may reduce their sustainability. According to the participants, plastic-free products are generally not available, and there is only a small range of loosed products when available. For instance,

"I try to consume more organic fruits and vegetables and not consuming, but I don't know the sustainability of those products due to the amount of packaging, especially plastic bags . . . it is difficult to find loosed organic fruits and vegetables on the shelf." [Sarah].

The excessive packing materials of food items generates a high volume of packaging waste, especially plastic and cardboard which is mostly disposed of landfills. On the other hand, the use of plastic packaging is creating a form of dissonance among the study participants, and they may abandon the ethical food consumption to resolve the negative effects of dissonance. This form of rationalisation is dominant in that if supermarkets only offer ethically produced foods in packaging materials, consumers with strong positive values may be reluctant to buy them despite being labelled as ethically sourced products. Also, the perception that producers are exploiting the trend towards an ethical and healthier lifestyle for marketing and profit purposes may prevent consumers from being consistent in their behaviour. For instance,

"Usually I am put off if it looks dodgy, too much marketed with all those claims instead of showing you really care." [Mila]

"I am trying harder every day for myself to consume more sustainably, buying food with little plastic but it is difficult to do that in Aberdeen, you would need togo to farmers markets, but for us, there is a little option. We have to go to the big supermarkets where everything is full of plastic." [Lisa].

\section{Understanding ethical buying behaviour}


Findings show that even though people professed to be ethical consumers, it is observed that their consumption behaviour is not always consistent with their professed belief. The fundamental question from the findings of this study is: why consumer dispositions and orientations do not always translate to actual ethical consumption behaviour? These findings challenge the dominant perceptions that consumers are increasingly demanding ethical products and willing to pay a premium price.

Despite the growing community of radical activists, including eco-warriors (De Hoop and Jehlička, 2017; Scarce, 2016), the explanation of why people engage in ethical food consumption is complex in that people's professed beliefs are not the true reflection of their actual buying behaviour. The evidence from this study suggests that people purchase ethical food products, that are sustainable, less than what they would prefer despite their endorsement of ethically produced foods. For instance:

"To be honest, it's rare that I buy ethical food products" [Nick]

"Not very often I would say. It is tricky. . . even if I buy organic products or freerange eggs there is still a lot of controversy behind it. Something to be truly organic, the field has to be grown for around like 50 years without anypesticides or chemicals and I do not think they are really doing that." [Peter].

According to the findings of this study, there is no universal explanation to what motivates consumers to purchase ethical foods. However, the findings of this study show that marketing strategies that are limiting the availability and accessibility of ethical foods are key barriers to ethical food consumption behaviour. Another barrier that is associated with the current marketing strategies is the price differentiator in that ethical food products are mostly pricey, especially for young adults. As summarised in Figure 1, perception of self and social context of consumption are the fundamental motivations for ethical food consumption behavior, particularly when ethical food products are available and accessible.

\section{Proposing Ethical Consumption Model}

The findings show that the study participants have strong positive feelings towards sustainability; however, there is a disparity between their dispositions and actual consumption of ethical food products which is influenced buying behaviour. Despite the positive attitudes, it is problematic for consumers to act on their inclinations due to many factors, such as price and products' availability, that may influence their buying behaviour (see Figure 1). Consistent with Ajzen's (1991) Theory of Planned Behaviour (TPB), this study argues that the perceived lack of control over buying behaviour due to the lack of 
accessibility/availability of ethical food products contributes to the inability of the study participants to translate their professed attitudes to the focal behaviour. Based on the integration of all the participants' comments as presented above, a theoretical model (Figure 1 ) is proposed to facilitate the understanding of ethical food consumption behaviour considering the observed disparity between the consumer's disposition and action.

\section{(Please insert Figure 1 here)}

According to the model, situational factors such as information, price, availability and accessibility of ethical products are major barriers to ethical food consumption and may indicate a lack of personal control over ethical food consumption behaviour. The available information should be sufficient in increasing consumers' knowledge and awareness about the consequences of (ethical) food products. Consistent with Wang and Hao (2018), the advent of the internet has changed consumption patterns and may facilitate the transition from pro-environmentalpredisposition, beliefs, and concerns into ethical and sustainability behaviour. While Pappas (2016) observed an increase in the media coverage of ethical food, the findings of this study suggest that ethical food consumption behaviour requires a lot of efforts due to the lack of accessibility and insufficient information about the benefits of ethical food products, such as organic and Fairtrade products. As a result, it is plausible to suggest that consumers may ascribe the responsibility of ethical food consumption to the market forces (including producers, retailers, and policymakers). According to Figure 1, the provision of adequate information about the availability of ethical food as well as the financial implications (cost/price), including the benefits of ethical food consumption is required for consumers to make informed decisions regarding their consumption.

Despite the observed importance of Knowledge in predicting green consumer behaviour, information alone may not be sufficient in explaining consumers' ethical consumption behaviour (Reisch et al., 2013; Kostadinova, 2016). This is mostly the case when there is a disconnect between information and knowledge (Oke and Kruijsen 2016) such that consumers are unaware of products' attributes in terms of their ethical and sustainability value (Kaufmann et al. , 2012; Vermeir and Verbeke, 2006). Marketing could play active roles in influencing ethical consumption in that the more the knowledge consumers obtain about the consequences and benefits of their actions, the higher the motivation to engage in ethical food consumption. As a result, the principles of social marketing which involve the application of conventional marketing techniques to influence consumers by pursuing prosocial and -environmental goals (Corner and Randall, 2011; Kaufmann et al., 2012; Peattie and Peattie, 2009) could be adopted to promote ethical food consumption. 
From the findings of this study, the product's price is an important determinant of consumer behaviour, and its effects may be similar across different age-groups and along the socioeconomic continuum considering the availability of cheap, mass-produced foods. This assertion is contrary to the segmentation strategies for marketing purposes using consumers' socio-demographics (see McCarthy and Liu, 2017). Another strong barrier based on the findings of this study is the lack of availability and accessibility of ethical food products in that people have limited choices in buying ethical food products, which may force them to opt for conventional products. The accessibility, varieties and low price of conventional products indicate that it is more convenient for consumers to buy such products compared to ethical food products. According to the literature (Bray et al., 2011; Vermeir and Verbeke, 2006), the interactions of many factors such as inertia, knowledge, locus of control, price and scepticisms of ethical claims may confound the positive effects of predisposition on ethical behaviour. The findings demonstrate that interventions (such as market- and policy-based) to promote ethical food consumption should focus on price, benefits, and social context of food consumption (see Figure 1). For consumers to change their behaviour, any intervention to promote ethical food consumption through its benefits should emphasise the personal, social, economic, and the environmental implications of ethical food consumption behaviour. This is consistent with the literature (such as Birch et al. , 2017; Reisch et al., 2013) that consumption of ethical food products, such as organic food, is influenced by perceived benefits, which could be personal andenvironmental.

\section{Discussion and Conclusion}

This study shows that motivations and barriers for ethical food consumption vary and there is no single definitive approach to influence consumer's behaviour although a combination of different factors (Figure 1 ) in designing a holistic intervention strategy may suffice. As presented in Figure 1, this study demonstrates that personal benefit is the main driver for ethical food consumption rather than the attribution of psychological traits. However, there is a possibility for interaction effects of personal benefit (such wellbeing) and psychological traits (such as self-identity and social norms) on ethical food consumption behaviour (Han and Hansen, 2012; Pham et al., 2019). According to Han and Hansen (2012), perception of self and other positive motivations can strengthen people's abilities to consume ethically irrespective of their psychological attributes. While studies (such as Pham et al., 2019; Kumar et al., 2016) have shown that consumers are more likely to act ecologically when driven by altruistic needs, the findings of this study show that motivations for ethical food consumption are less altruistic. According to this study, motivations for ethical food consumption are mostly egoistic values such as personal health and wellbeing. However, altruistic and egoistic values can simultaneously drive ethical food consumption behaviour 
based on consumer's belief-systems regarding the importance (and implications) of ethical food consumption. This knowledge is fundamental when branding and marketing ethical lifestyle, especially when ethical food consumption is perceived to be outside the consumers' volitional control. The findings of this study are consistent with other studies (such as Birch et al., 2017; Pham et al., 2019) that consumers may prioritise their health over other motivations while paying more to achieve their personal goals.

Also, consumers are of ten driven by self-actualisation that defines their self-identity in that ethical food consumption of ten describes consumer's identity as ethical. Consistent with Bandura's (1977) concept of self-efficacy, self-identification as ethical consumers may determine the tendency to consume ethical food products despite the difficulties in purchasing them. Although altruistic values contribute to the consumers' buying decision, the desire to be consistent in their personality and identity, such as vegans/vegetarians, suggest that their personal needs are prioritised over altruistic actions (see Figure 1). The findings are supported by previous studies (such as Birch et al., 2017; Kareklas et al., 2014) that consumers are more inclined to engage in ethical buying behaviour after fulfilling their personal and egoistic needs. Nevertheless, the study participants expressed a deep concern for the environment and animal welfare in that the killing of animals for human consumption is considered to be unethical and unacceptable, and not align with their personality traits. Moreover, the findings of this study show that the social contexts of food consumption are critical to ethical food consumption (see Figure 1) in that young adults tend to be influenced by their acquaintances, especially families and friends. The findings are consistent with Pickett-Baker and Ozaki (2008), who reported a strong relationship between sustainable consumption behaviour and injunctive or descriptive social norms. While young adults feel motivated by the dominant social norms, knowledge and information (Figure 1) are crucial in their decision-making to purchase and consume ethical food products. If efforts of active information gathering are robust, using the correct medium, consumers will have sufficient knowledge about the impacts of food production and consumption on the whole ecosystem. Implicit and explicit knowledge about how the food industry works across the food supply

chain and the benefits of ethical production may increase consumers' awareness about the consequences of food consumption.

While environmental knowledge contributes to ethical food consumption (Kaufmann et al., 2012), it may interact with contextual attributes when making consumption decisions.

Consistent with the literature (such as Oke and Kruijsen, 2016; Vermeir and Verbeke, 2006), Figure 1 shows that reliable and precise information on ethical behaviours is imperative during the decision-making process. However, information to promote ethical food products 
should also focus on interventions that address the health and social benefits of ethical food consumption rather than the environmental benefits alone (Figure 1).

Having demonstrated that the social context, especially family and friends, represents a key influence in consumption behaviour, there is a need for producers and retailers to incorporate some aspect of social consciousness in their operations, especially when promoting ethical food products. According to the findings, the marketing efforts of food producers, wholesalers, and retailers are crucial in increasing the awareness of ethical products and contribute to how the responsibility for ethical food consumption is attributed. Although conventional marketing has been criticised for adopting wrong strategies, the concept of social marketing (Rettie et al., 2012) could be introduced to promote ethical food consumption and across its value chain. Considering that this study focuses on young adults, the internet is an important medium that has a major impact on consumer's buying behaviour due to the growth of online marketing. The marketing strategies of ethical food products may be less effective and sometimes even result in undesirable outcomes if the strategy is perceived to be promoting economic agenda at the detriment of personal, social, and environmental benefits. The major question is whether humanity can redeem itself by protecting the planet from the inevitable destruction due to the overconsumption of natural resources. While consumers may express a strong desire to consume ethically (Birch et al., 2017; Bray et al., 2011; Rettie et al., 2012), this study argues that the extent to which this consumption behaviour contributes to the idea of sustainability is another complex issue that worth exploring.

Although there is an increasing concern, especially among young adults, about the idea of sustainability, this study concludes that such concern may not necessarily translate to ethical consumption. It should be noted that the findings of this study are based on small, but adequate, sample size (Guest et al., 2006), further study is required, especially to explore the utility of the proposed model (Figure 1 ) in other contexts, and possibly with larger sample size. This could assist in developing a measuring instrument, including scales, items, and hypotheses, in testing the validity and reliability of the model using a quantitative approach.

\section{References}

Ajzen, I. (1991), “The theory of planned behavior”, Organizational Behavior and Human Decision Processes, Vol. 50 No. 2, pp. 179-211.

Baker, L., Gemmill-Herren, B. and Leippert, F. (2019), “Accelerating Transformations to Sustainable Food Systems. Biovision Foundation and Global Alliance for the Future of

Food", available at: 


\section{https://www.biovision.ch/fileadmin/pdf/e/news/BeaconsOfHope_Report_082019.pdf} (accessed 17 January 2020).

Baker, J. M. (2003), Business and management research: how to complete your research project successfully, Westburn Publishers Ltd.

Bandura, A. (1977), "Self-efficacy: Toward a unifying theory of behavioral change", Psychological Review, Vol. 84 No. 2, pp. 191-215.

Bazeley, P. and Jackson, K. (2013), Qualitative data analysis with NVivo, Sage Publications Limited.

Birch, D. , Memery, J. and Kanakaratne, M. (2017), “The mindful consumer: Balancing egoistic and altruistic motivations to purchase local food", Journal of Retailing and Consumer Service, Vol. 40, pp. 221-228.

Bray, J., Johns, N. and Kilburn, D. (2011), “An exploratory study into the factors impeding ethical consumption”, Journal of Business Ethics, Vol. 98 No. 4, pp. 597-608.

Bryman, A. (2016), Social research methods, Oxford University Press.

Corner, A. and Randall, A. (2011), "Selling climate change? The limitations of social marketing as a strategy for climate change public engagement", Global Environmental Change, Vol. 21 No. 3, pp. 1005-1014.

Creswell, J. and Creswell, J. (2018), Research design: qualitative, quantitative and mixed methods approaches, 5th edition, SAGE, London.

Crist, E., Mora, C. and Engelman, R. (2017), "The interaction of human population, food production, and biodiversity protection”, Science, Vol. 356 No. 6335, pp. 260-264.

Davies, D. and Dodd, J. (2002), “Qualitative research and the question of rigor”, Qualitative Health Research, Vol. 12 No. 2, pp. 279-289.

De Hoop, E. and Jehlička, P. (2017), “Reluctant pioneers in the European periphery? Environmental activism, food consumption and "growing your own", Local Environment, Vol. 22 No. 7, pp. 809-824.

Ethical Consumer Research Association (2018), “Ethical Consumer Markets Report 2018”, available at: https://www.ethicalconsumer.org/sites/default/files/inline-

files/EC\%20Markets\%20Report\%202018\%20FINAL.pdf (accessed 05/10/2019).

Fraj, E. and Martinez, E. (2006), "Environmental values and lifestyles as determining factors of ecological consumer behaviour: an empirical analysis”, Journal of Consumer Marketing, Vol. 23 No. 3, pp. 133-144. 
Govind, R. , Singh, J. J., Garg, N. and D’Silva, S. (2019), “Not walking the walk: How dual attitudes influence behavioral outcomes in ethical consumption”, Journal of Business Ethics, Vol. 155 No. 4, pp. 1195-1214.

Guest, G., Bunce, A. and Johnson, L. (2006), “How many interviews are enough? An experiment with data saturation and variability", Field Methods, Vol. 18 No. 1, pp. 59-82.

Han, Y. and Hansen, H. (2012), “Determinants of Sustainable Food Consumption: A metaanalysis using a traditional and a structural equation modelling approach", International Journal of Psychological Studies, Vol. 4 No. 1, pp. 22-45.

Harari, Y. N. (2011), Sapiens. Harper, New York, NY.

Insight Department (2015), “Trends for 2016”, available at:

https: / /www. visitscotland.org/binaries/content/assets/dot-org/pdf/research-

papers/insights-trends-2016.pdf (accessed 17 October 2019).

Kareklas, I. , Carlson, J. and Muehling, D. (2014), ““' eat organic for my benefit and yours": egoistic and altruistic considerations for purchasing organic food and their implications for advertising strategists", Journal of Advertising, Vol. 43 No. 1, pp. 18-32.

Kaufmann, H. R., Panni, M. F. A. K. and Orphanidou, Y. (2012), “Factors affecting consumers' green purchasing behavior: An integrated conceptual framework", Amfiteatru Economic Journal, Vol. 14 No. 31, pp. 50-69.

Kostadinova, E. (2016), "Sustainable consumer behavior: Literature overview”, Economic Alternatives, Vol. 2, pp. 224-234.

Kumar, B., Manrai, K. A. and Manrai, A. L. (2016), “Purchasing behaviour for environmentally sustainable products: A framework and empirical study", Journal of Retailing and Consumer Services, Vol. 34, pp. 1-9.

McCarthy, B. and Liu, H. B. (2017), “Food waste and the 'green' consumer”, Australasian Marketing Journal, Vol. 25 No. 2, pp. 126-132.

Oke, A. and Kruijsen, J. (2016), "The importance of specific recycling information in designing a waste management scheme”, Recycling, Vol. 1 No. 2, pp. 271-285.

Pappas, N. (2016), “Marketing strategies, perceived risks, and consumer trust in online buying behaviour”, Journal of Retailing and Consumer Services, Vol. 29, pp. 92-103.

Peattie, K. and Peattie, S. (2009), "Social marketing: a pathway to consumption reduction?”, Journal of Business Research, Vol. 62 No. 2, pp. 260-268. 
Pham, T. H., Nguyen, T. N., Phan, T. T. H. and Nguyen, N. T. (2019), "Evaluating the purchase behaviour of organic food by young consumers in an emerging market economy", Journal of Strategic Marketing, Vol. 27 No.6, pp. 1-17.

Picket-Baker, J. and Ozaki, R. (2008), "Pro-environmental products: marketing influence on consumer purchase decision", Journal of Consumer Marketing, Vol. 25 No. 5, pp. 281 293.

Reisch, L., Eberle, U. and Lorek, S. (2013), "Sustainable food consumption: an overview of contemporary issues and policies", Sustainability: Science, Practice and Policy, Vol. 9 No.

2, pp. 7-25.

Rettie, R., Burchell, K. and Riley, D. (2012), “Normalising green behaviours: A new approach to sustainability marketing”, Journal of Marketing Management, Vol. 28 No. 3-4, pp. 420-444.

Ryan, G. W. and Bernard, H. R. (2003), “Techniques to identify themes”, Field Methods, Vol. 15 No. 1 , pp. 85-109.

Sakadevan, K. and Nguyen, M. L. (2017), “Livestock production and its impact on nutrient pollution and greenhouse gas emissions", In Advances in Agronomy, Vol. 141, pp. 147-184, Academic Press.

Sala, S., McLaren, S. J., Notarnicola, B., Saouter, E. and Sonesson, U. (2017), “In quest of reducing the environmental impacts of food production and consumption", Journal of Cleaner Production, Vol. 140, pp. 387-398.

Scarce, R. (2016). Eco-warriors: Understanding the radical environmental movement, Routledge.

Smith, J. and High, M. M. (2017), “Exploring the anthropology of energy: ethnography, energy and ethics”. Energy Research and Social Science, Vol. 30, pp. 1-6.

The Vegan Society (2019), "Statistics", available at:

https: //www. vegansociety.com/news/media/statistics (accessed 05 January 2020).

Vantamay, N. (2018), "Investigation and recommendations on the promotion of sustainable consumption behavior among young consumers in Thailand", Kasetsart Journal of

Sciences, Vol. 39 No 1, pp. 51-58.

Vermeir, I. and Verbeke, W. (2006), "Sustainable food consumption: Exploring the consumer "attitude-behavioral intention" gap", Journal of Agricultural and Environmental Ethics, Vol. 19 No. 2, pp. 169-194. 
Wang, Y. and Hao, F. (2018), “Does internet penetration encourage sustainable consumption? A cross-national analysis", Sustainable Production and Consumption, Vol. 16, pp. 237-248. 
Ethical and sustainable food consumption behaviour of young adults.

Table:

\begin{tabular}{llll}
\multicolumn{4}{l}{ Table 1: } \\
Name & Gendicipants' & Age & Profile \\
& & & \\
\hline Tom & Male & 21 & Student \\
Lisa & Female & 26 & Buyer \\
Nick & Male & 28 & Engineer \\
Mike & Male & 23 & Student \\
Mila & Female & 28 & Social Worker \\
Lynn & Female & 27 & HR Consultant \\
Sarah & Female & 26 & Teacher \\
Peter & Male & 25 & Banker \\
Jenny & Female & 22 & Student \\
Lizzy & Female & 18 & Student \\
\cline { 2 - 4 }
\end{tabular}


Ethical and sustainable food consumption behaviour of young adults.

Figure:

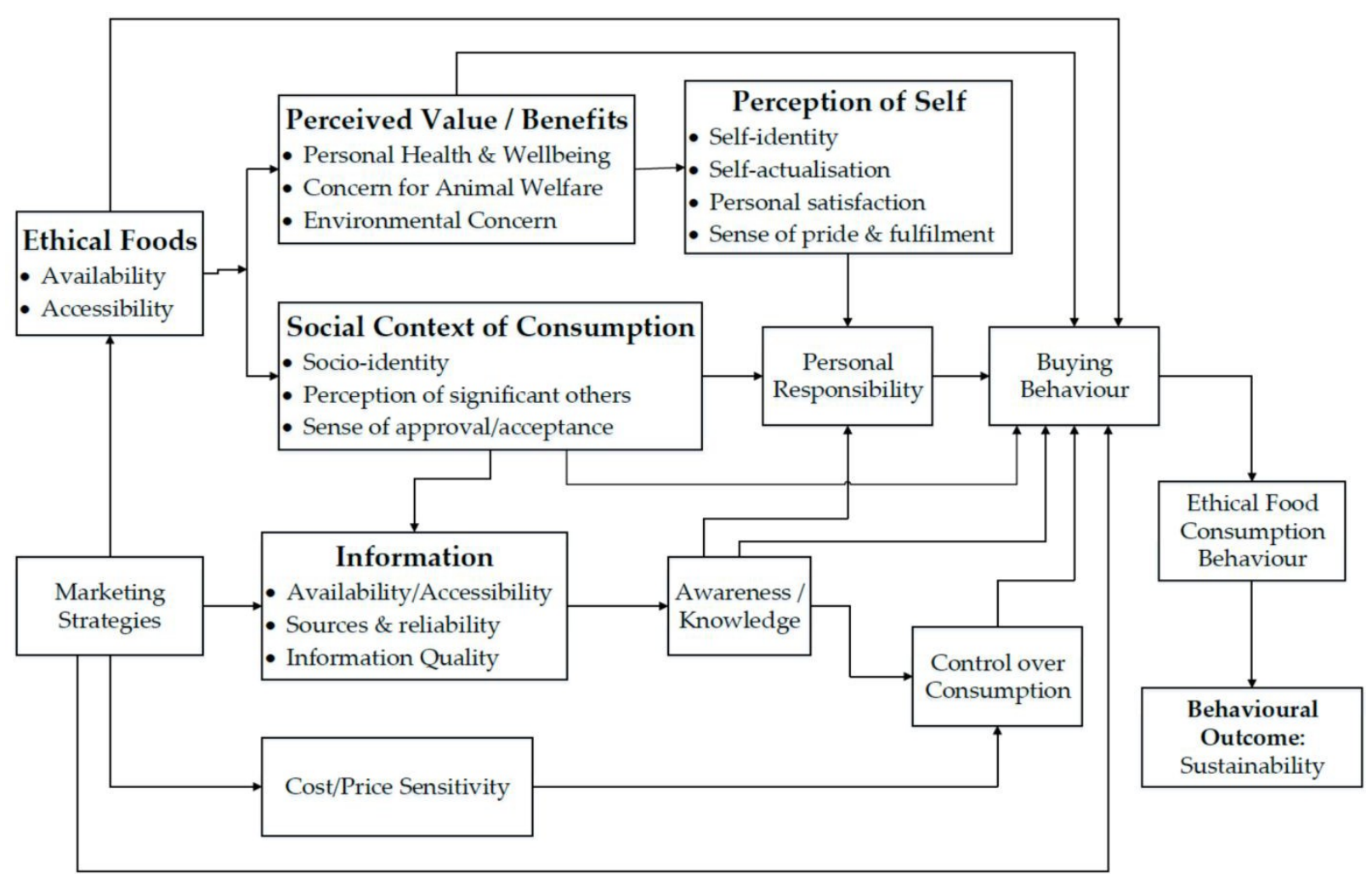

Fig. 1: Ethical and Sustainable Consumption Model (Source: Authors) 